\title{
Electric Arc Furnace Slag as Coarse Recycled Aggregate for Concrete Production
}

\author{
Flora Faleschini ${ }^{1}$ - Katya Brunelli ${ }^{2}$ - Mariano Angelo Zanini ${ }^{1} \cdot$ Manuele Dabalà $^{2}$. \\ Carlo Pellegrino ${ }^{1}$
}

Published online: 1 October 2015

(C) The Minerals, Metals \& Materials Society (TMS) 2015

\begin{abstract}
Electric arc furnace (EAF) slag is a by-product of steel production in electric arc furnaces. Several studies have tried to demonstrate its suitability in civil engineering application, such as in bituminous mixtures and cementbased materials, due to its good physical, chemical and mineralogical properties. Particularly the re-use as coarse aggregate for concrete production has been shown to be a promising valorisation, when physical and chemical stability is guaranteed. Additionally, EAF slag's high mechanical strength makes it suitable for high-performance concrete production. In this work three EAF concretes, with various cement content and also with silica fume addition, were compared with a reference concrete, to identify a convenient mix design to reach a concrete strength class between C50/60 and C60/75. Mechanical strength was evaluated analysing compressive and tensile strength, and elastic modulus. A complementary microstructural analysis was performed after the failure of the specimens, with the aim of analysing the morphology of the interfacial transition zone. Results indicate that the use of EAF slag in concrete allows reaching higher compressive strength than with coarse natural aggregates. EAF slag application in structural concrete promotes also the reduction of cement content in the mix to reach the same strength class.
\end{abstract}

The contributing editor for this article was Yiannis Pontikes.

Katya Brunelli

katya.brunelli@unipd.it

1 Department of Civil, Environmental and Architectural Engineering, University of Padova, Via Marzolo 9, 35131 Padua, Italy

2 Department of Industrial Engineering, University of Padova, Via Marzolo 9, 35131 Padua, Italy
Keywords EAF slag - Concrete - Recycled aggregates · Mechanical properties $\cdot$ SEM $\cdot$ ITZ

\section{Introduction}

During the last decades, the promotion of recycling in concrete industry has been demonstrated to represent a valid route for sustainable development, leading to prevention in natural resources consumption, and to a re-use of recycled materials, avoiding their landfilling [1]. Accordingly, a number of researches have focused mainly on the use of recycled aggregates coming from construction and demolition (C\&DW) operations [2, 3], but also, more recently, on metallurgical slags [4-6].

The quality of the aggregates significantly influences concrete properties, which is responsible for most of the physical and mechanical properties of the material. Their characteristics are particularly important with reference to high-performance concrete (HPC), characterised by a significant improvement of many properties with respect to ordinary concrete (OC), i.e. higher mechanical strength, better workability and durability. In this case, the use of recycled old concrete aggregates is mostly not recommended in HPC design, due to their high absorption capacity, unstable property and weak strength [7]. However, the sustainability goal, which drives the most of the current social challenges, asks for an increasingly re-use of wastes and by-products, especially when dealing with industries characterised by high environmental impacts, such as cement and concrete industry. In this field, the reuse of recycled aggregates coming from metallurgical industry, e.g. electric arc furnace (EAF) slag, may represent a key solution to achieve both the sustainability and mechanical/durability performances' goals [8]. 
EAF slag is a by-product of steel production, currently partially re-used in asphalt concrete [9]. However, huge quantities of this material are still landfilled. Different from other recycled aggregates, EAF slag has very good mechanical properties: it is a crushed product with black colour stone appearance and a rough surface texture. It has high abrasion resistance, low aggregate crushing value (ACV) [10] and excellent resistance to fragmentation. Those properties make EAF slag particularly suitable in concrete applications, also for structural purposes [11], leading to an improvement of mechanical strength of the hardened concretes. However, it is worth noting that this artificial material may be subjected to volumetric instability problems, due to the possible expansion of free $\mathrm{CaO}$ and free $\mathrm{MgO}$, as reported in [12]. Expansion phenomena would hinder EAF slag use in civil engineering applications, decreasing highly slag quality. Several factors contribute to the presence of free lime and periclase, dealing particularly with the steelmaking process and to the slag cooling, from furnace to environmental temperature. Pretreatment operations, such as weathering for at least 90 days and spraying with water for a couple of days, enhance volumetric stability and limit volumetric expansion [13, 14]. Different from the non-weathered slag, generally the pre-treated one does not contain free lime at high percentages.

Recent results published by Arribas et al. [15] have obtained a better quality of the matrix-slag aggregate interfacial transition zone (ITZ), which may explain the enhanced mechanical properties of EAF concrete. However, additional research is required to confirm these relevant findings.

This study is part of a wider research program, which began more than 6 years ago, aiming to improve the knowledge about EAF slag concretes, leading to a sustainable use of this material in the civil engineering field. Also an initiative between several European research groups, where some of the authors are involved, is currently active, with the aim of establishing new pre-normative standards in this field. With this regard, particular attention is currently paid to quality assurance of slag pretreatment processes, and to durability-related aspects of EAF concrete.

Here, a characterisation of the EAF slag has been done, through the analysis of the main chemical, physical and microstructural properties. Additionally, four experimental concretes were casted, including EAF slag as coarse aggregate. Mechanical properties were experimentally investigated; additionally, a microstructural characterisation was performed to observe the morphology of EAF concrete, particularly, at the interface with the cementitious matrix.
Table 1 Main physical properties of the aggregates

\begin{tabular}{llll}
\hline & EAF slag & NA-sand & NA-gravel \\
\hline Size $(\mathrm{mm})$ & $4-16$ & $0-4$ & $4-16$ \\
Apparent density $\left(\mathrm{kg} / \mathrm{m}^{3}\right)$ & 3854 & 2704 & 2700 \\
Water absorption $(\%)$ & 0.95 & 1.18 & 1.04 \\
Shape & Sharp-pointed & Roundish & Roundish \\
\hline
\end{tabular}

\section{Materials and Experimental Methods}

\section{Materials}

The materials used for all the mixes are Ordinary Portland Cement type I 52.5R class, as defined in EN 197-1 [16]; natural calcareous sand with a maximum size of $4 \mathrm{~mm}$ was considered as fine aggregate; siliceous coarse aggregates with a maximum size of $16 \mathrm{~mm}$; EAF slag aggregates, with a maximum size of $16 \mathrm{~mm}$ maximum size, described in the following section; a super-plasticiser sulphonated naphthalene admixture. In one mix, condensed silica fume (SF) obtained from BASF was used. Physical properties of the aggregates are listed in Table 1.

\section{EAF Slag: Characterisation}

Steel slag used in this experimental investigation was supplied by a local steel factory in the northeastern part of Italy. After cooling, the slag was subjected to screening, crushing, sieving and magnetic separation. Then a pretreatment consisting in exposing the slag to outdoor weather and regular water spraying it for 90 days was applied.

Dynamic leaching tests of the slag aggregates were carried out with a liquid to solid ratio of 5 , at $20^{\circ} \mathrm{C}$. The leaching test results, performed preliminarily to the use of the slag, evidenced that all the values were under the limit for non-toxic residues, according to the Italian normative.

A representative amount of slag aggregates, with a maximum size of $16 \mathrm{~mm}$ maximum size, was pulverised to a fine powder for the chemical and mineralogical analysis. The chemical analysis of the slag was carried out by X-ray fluorescence, using a Spectro X-Lab 2000 instrument. The mineralogical composition of the pre-treated slag was analysed with a Siemens D5000 diffractometer, using $\mathrm{CuK} \alpha$ radiation, $40 \mathrm{kV}$ and $30 \mathrm{~mA}$.

The microstructural analysis was performed with a Cambridge Stereoscan 440 scanning electron microscope, equipped with a Philips PV9800 EDS. The images were taken in backscattered (BSE) electron mode. For this analysis, the cross section of the slag aggregate was 
Table 2 Chemical composition of the slag

\begin{tabular}{ll}
\hline Oxide & wt\% \\
\hline $\mathrm{MgO}$ & 2.97 \\
$\mathrm{Al}_{2} \mathrm{O}_{3}$ & 10.20 \\
$\mathrm{SiO}_{2}$ & 14.56 \\
$\mathrm{CaO}$ & 30.30 \\
$\mathrm{Cr}_{2} \mathrm{O}_{3}$ & 2.67 \\
$\mathrm{MnO}$ & 4.34 \\
$\mathrm{FeO}$ & 33.28 \\
\hline
\end{tabular}

encapsulated in epoxy resin and then mechanically polished using standard metallographic procedures.

The chemical composition of the pre-treated slag is shown in Table 2. The most abundant oxides corresponded to $\mathrm{Fe}_{2} \mathrm{O}_{3}, \mathrm{CaO}, \mathrm{SiO}_{2}$ and $\mathrm{Al}_{2} \mathrm{O}_{3}$. The investigated slag resulted in basic, $M_{\mathrm{b}}(\mathrm{CaO}+\mathrm{MgO}) /\left(\mathrm{SiO}_{2}+\mathrm{Al}_{2} \mathrm{O}_{3}\right)>1$, with a value of 1.3. According to Daugherty et al., the slag should be mainly constituted of crystalline phases [17].

From XRD analysis, it was confirmed that the slag consisted mainly of crystalline material. Wüstite, larnite and gehlenite were the main phases present in the slag, in accordance with the composition of the slag (Fig. 1).

In Fig. 2, the SEM-BSE image of cross section of the slag agglomerate is shown, where it is possible to recognise the different phases. The EDS analysis carried out on the main phases evidenced that the lighter zones (point 1) were rich in $\mathrm{Fe}$, with $\mathrm{Mn}$ and a low amount of $\mathrm{Mg}$, suggesting the presence of a solid solution of (Fe, Mn, $\mathrm{Mg}$ )O, structurally close to the wüstite $(\mathrm{FeO})$, whose presence was detected by XRD analysis. The darker zones (point 2), constituted of $\mathrm{Ca}$ and $\mathrm{Si}$, were attributed to the larnite phase, in accordance with XRD analysis. The lighter component of eutectic phase was composed of (Fe, Mn)O, that is wüstite phase, whereas the darker component, constituted of $\mathrm{Ca}$, Si and $\mathrm{Al}$, was attributed to gehlenite phase, in agreement with XRD analysis. The isolated phase (point 3), enriched in $\mathrm{Cr}$ with $\mathrm{Mn}, \mathrm{Fe}, \mathrm{Al}$ and $\mathrm{Mg}$, was related to magnesiochromite phase, though its presence was not revealed by XRD analysis, due to its low amount.

From XRD and SEM analysis, the presence of free $\mathrm{MgO}$ and free $\mathrm{CaO}$ was not detected.

\section{Experimental Methods}

Four concrete mixtures were designed: one reference/control containing only natural aggregates (NA), and three EAF slag concretes, where the whole coarse aggregates were substituted with EAF slag. The mixtures' details are shown in Table 3: letter $C$ denotes control concrete, whereas letter $E$ indicates EAF concrete. Water/binder ratio was maintained constant and was equal to 0.4 , as well as the SP content; aggregate grading curves were obtained

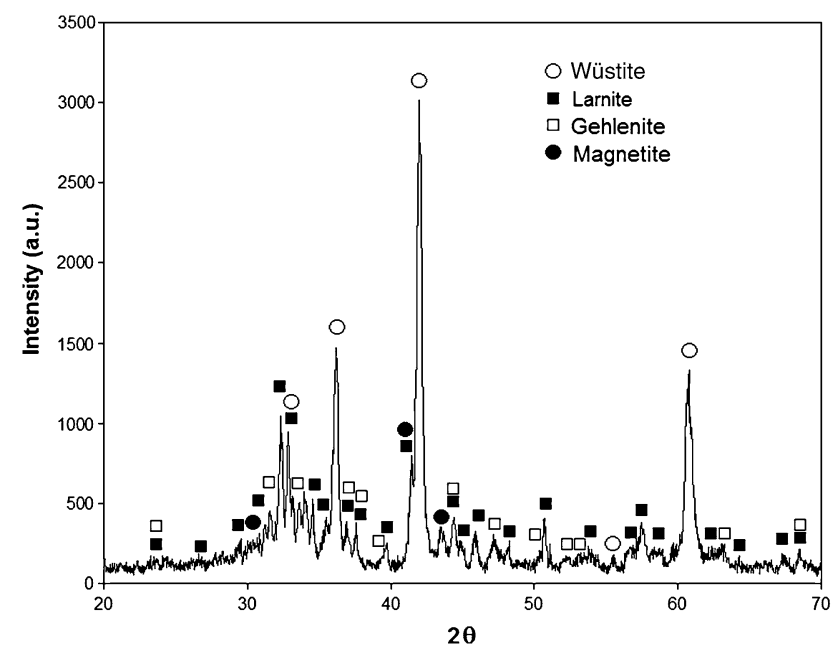

Fig. 1 XRD pattern of the slag aggregates

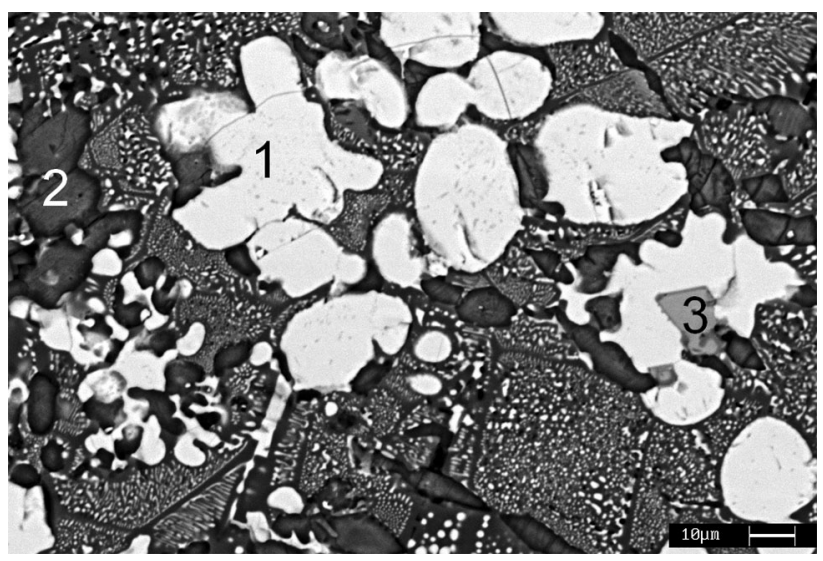

Fig. 2 SEM-BSE image of the cross section of the slag aggregate

Table 3 Mixtures' details (expressed per $1 \mathrm{~m}^{3}$ )

\begin{tabular}{lllll}
\hline & Mix C & Mix E1 & Mix E2 & Mix E-SF \\
\hline Cement $\left(\mathrm{kg} / \mathrm{m}^{3}\right)$ & 400 & 400 & 350 & 400 \\
$\mathrm{SF}\left(\mathrm{kg} / \mathrm{m}^{3}\right)$ & - & - & - & 60 \\
Water $\left(\mathrm{kg} / \mathrm{m}^{3}\right)$ & 160 & 160 & 140 & 184 \\
$w /(c+\mathrm{SF})$ & 0.4 & 0.4 & 0.4 & 0.4 \\
Coarse NA $\left(\mathrm{kg} / \mathrm{m}^{3}\right)$ & 1008 & - & - & - \\
Coarse EAF $\left(\mathrm{kg} / \mathrm{m}^{3}\right)$ & - & 1408 & 1476 & 1370 \\
Fine NA $\left(\mathrm{kg} / \mathrm{m}^{3}\right)$ & 832 & 832 & 872 & 810 \\
$\mathrm{SP}(\%)$ & 1.2 & 1.2 & 1.2 & 1.2 \\
\hline
\end{tabular}

according to Bolomey curve. In one mix, SF addition was used at $15 \%$ on cement weight. The performance required of the mixes is to reach a concrete strength class between C50/60 and C60/75, with an S4 consistency class, as defined in [18]. 
After mixing, specimens were properly compacted, covered to limit evaporation, demolded $24 \mathrm{~h}$ after casting, and then cured in standard temperature $\left(20 \pm 2{ }^{\circ} \mathrm{C}\right)$ and humidity ( $\mathrm{RH} \geq 95 \%)$ conditions until the time of testing. Compressive strength was measured after 7 and 28 days on cubic specimens with $150 \mathrm{~mm}$ side, according to [19]. Cylindrical specimens with $100 \mathrm{~mm}$ diameter and $200 \mathrm{~mm}$ length were used for measuring the tensile strength by means of splitting test [20], and to evaluate the secant modulus of elasticity by means of cyclic load test [21]. In all the cases, results are the average of at least three specimens per test.

The characteristics of the matrix of Mix C and Mix E1 should be the same, because of the same cement, water and fine fraction dosages, and the same aggregate grading curve. Accordingly, after compressive tests, specimens' surfaces of those two concretes were examined through scanning electron microscope (SEM) aiming to analyse matrix-coarse aggregate interfacial regions. SEM-BSE images were taken at an acceleration voltage of $25 \mathrm{kV}$. Also Mix E-SF has been analysed with microscopic observation, in order to detect possible differences in the cementitious matrix.

\section{Results and Discussion}

\section{Fresh and Hardened Concrete Properties}

The concretes produced in this experimental campaign belong to the S4 consistency class. Fresh concrete properties are listed in Table 4 together with the results of mechanical strength tests, including compressive, tensile strength and elastic modulus evaluated at 28 days. The increase in concrete density is one of the most remarkable results obtained: the use of EAF slag causes a maximum

Table 4 Fresh concrete properties and the results of mechanical strength tests

\begin{tabular}{|c|c|c|c|c|}
\hline & Mix $C$ & Mix E1 & Mix E2 & Mix E-SF \\
\hline \multicolumn{5}{|c|}{ Fresh concrete properties } \\
\hline Density $\left(\mathrm{kg} / \mathrm{m}^{3}\right)$ & 2477 & 2935 & 3007 & 2777 \\
\hline Slump (mm) & 210 & 170 & 160 & 210 \\
\hline \multicolumn{5}{|c|}{ Hardened concrete properties -7 days } \\
\hline Density $\left(\mathrm{kg} / \mathrm{m}^{3}\right)$ & 2470 & 2890 & 2982 & 2765 \\
\hline$f_{\text {cm,cube }}(\mathrm{MPa})$ & 45.7 & 69.05 & 60.6 & 54.6 \\
\hline \multicolumn{5}{|c|}{ Hardened concrete properties_-28 days } \\
\hline Density $\left(\mathrm{kg} / \mathrm{m}^{3}\right)$ & 2510 & 2930 & 2967 & 2790 \\
\hline$f_{\text {cm,cube }}(\mathrm{MPa})$ & 56.4 & 76.4 & 73.9 & 65.0 \\
\hline$f_{\text {ctm }}(\mathrm{MPa})$ & 4.50 & 5.65 & 5.37 & 4.65 \\
\hline$E_{\mathrm{cm}}(\mathrm{GPa})$ & 38.5 & 49.5 & 49.2 & 45.5 \\
\hline
\end{tabular}

increase of about $21 \%$ in the specific gravity of fresh concrete (Mix E2). This is due to the high density of the slag, which is indeed constituted of iron and metallic oxides, providing a higher specific gravity; in this case, the amount of Fe-contaning phases is more than $30 \%$ in weight. Additionally, the slag used in this experimental campaign has a low porosity, which contributes in increasing its specific gravity. Mix E-SF has lower density with respect to the other EAF concretes, due to a reduced content of EAF slag aggregates in the mixture. Concerning concretes' fresh properties, generally the use of EAF slag decreases workability, as obtained also in other previous works [4, 11]: Mix E1 is characterised by the lower slump value $(-19 \%)$, whereas Mix E2, which contains a slightly higher amount of sand, has a slump loss of about $14 \%$. This does not occur in Mix E-SF, due to the higher water content in the mix.

A relevant improvement in the compressive and tensile strength, and in elastic modulus, is obtained when EAF slag replaces the coarse natural aggregates. The most relevant compressive strength increase has been observed in Mix E1, which has the same mixture proportion than the control concrete. Compressive strength of Mix E2, which contains $50 \mathrm{~kg} / \mathrm{m}^{3}$ less than Mix E1, is not significantly affected by this mix variation: the remarkable reduction in cement content is balanced by the higher EAF aggregate content, and the lower absolute water content $(-12.5 \%)$. Mix E-SF has obtained a strength increase with respect to the control mixture, however, its compressive strength is $15 \%$ less than Mix E1 $f_{\text {c,cube }}$. This result may be explained by two factors: the relative high $w /(c+\mathrm{SF})$ ratio used in this work, and the greater absolute water content in the mix $(+15 \%)$. Concerning the former, generally, SF incorporation results in significant improvement of the resistance only with $w /(c+\mathrm{SF})$ ratio lower than 0.3 .

From Table 4 , it is seen that the increase of tensile strength due to the use of EAF slag is remarkable. From the observations of concrete surfaces after splitting failure (Fig. 3), it is perceived that a better bonding between the aggregates and the cementitious matrix occurs when EAF slag aggregates are used. This result is in agreement with the compressive strength increase, and may be assigned to the better quality of the ITZ, as also obtained in a recent publication [15], and to the higher strength of the slag itself. However, a specific study based on microscopic observation (see next section) is necessary to analyse in detail this macroscopic observation.

Concerning the elastic modulus, also in this case an increase is observed for EAF concretes, due to the better mechanical properties of the slag. The modulus is obtained from cyclic loading of specimens under compressive test, between $f_{c} / 10$ and $f_{c} / 3$. In this range, the stress-strain curve is linear for all the analysed mixes. 

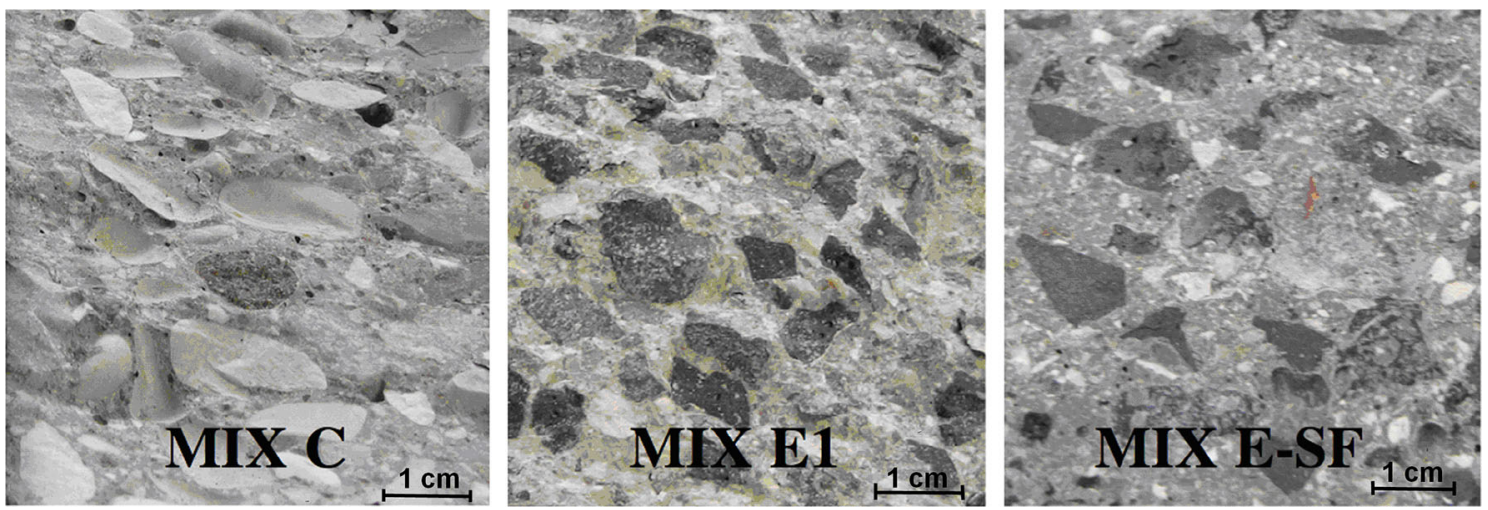

Fig. 3 Specimens' surfaces after splitting failure

\section{Microscopic Observations}

From a macroscopic observation, failure after compressive test at 28 days occurred both in the paste and in the NA in the case of the control mix (Fig. 4a). On the contrary, in all the mixes containing EAF slag aggregates, the failure occurred always in the paste (Fig. 4b). This indicates, at a first sight, a better quality of the EAF aggregates with respect to the coarse natural aggregates used in the control mixture.

However, to explain the enhanced properties observed in terms of tensile and compressive strength, the analysis of the ITZ has been considered to be useful, particularly with respect to the better bond observed between EAF slag and cementitious matrix. The ITZ is considered as a $15-40 \mu \mathrm{m}$ zone which surrounds the aggregates, characterised by high porosity, high content of Portlandite and the presence of ettringite [22]. It could be detected through SEM-BSE analysis, as a darker boundary of a couple of $\mu \mathrm{m}$ width in the nearest of the aggregates. Depending on the quality of the aggregates, cement and mixture dosages, the width of this zone can vary (lower for well-performed mixes, with reduced $w / c$ ratios). Its quality affects significantly both hardened and fresh concrete properties, being in most cases the weakest element of a conglomerate.
From the SEM analysis it was possible to observe, also at a microscopic level, that the cracks developed both in the cement paste and in the natural aggregates (Mix C), whereas EAF slag remained compact, and the failure was observed only in the cement paste and aggregates boundary (Fig. 5).

Figure 6 shows a slag particle (light-grey), surrounded by the ITZ and the cement paste with some sand particles, taken from Mix E1. Cracks are developed through the sand

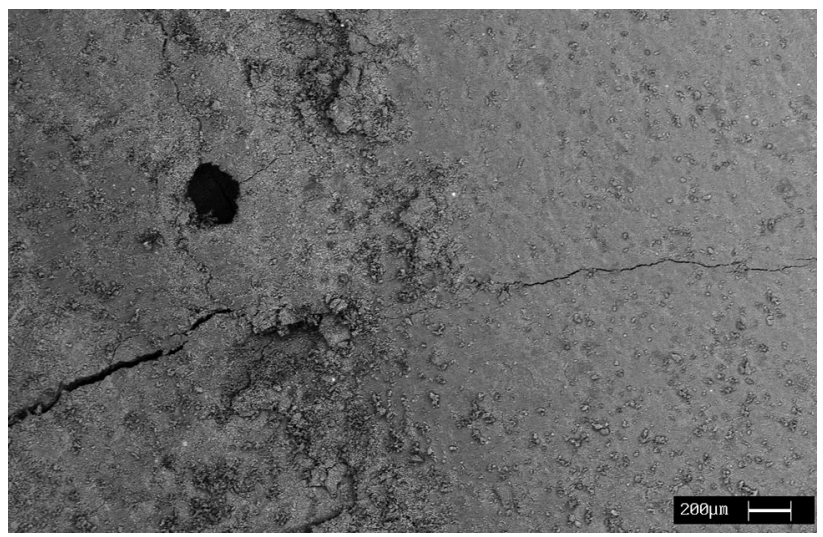

Fig. 5 SEM-BSE image of Mix C
Fig. 4 Specimens' surfaces after compressive failure: a Mix C; b Mix E1
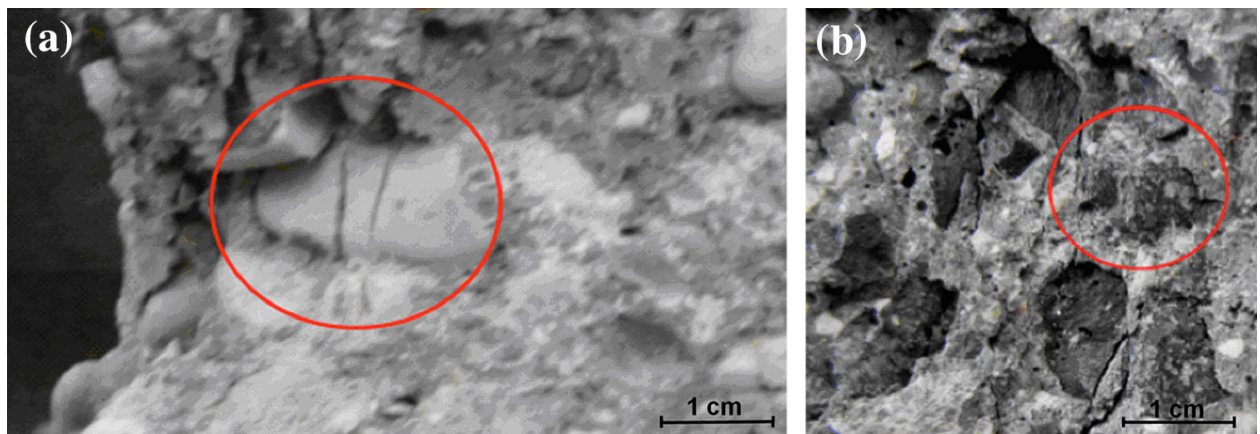


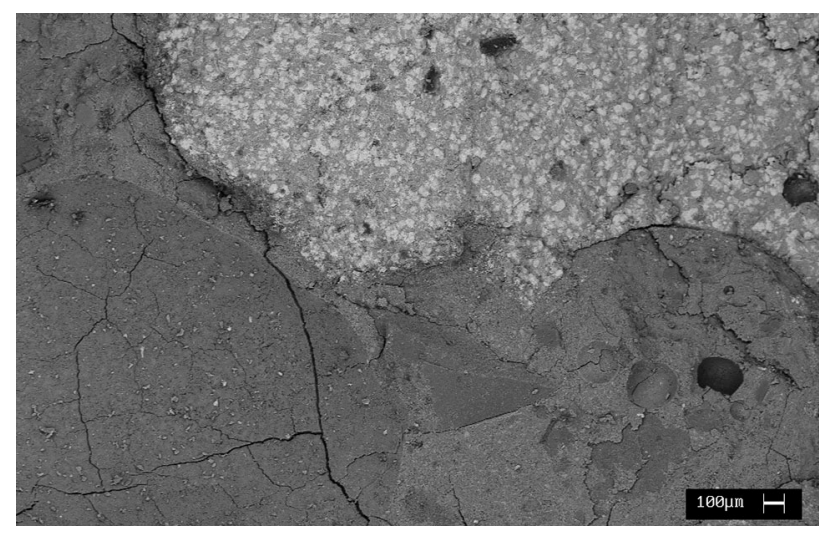

Fig. 6 SEM-BSE image of Mix E1

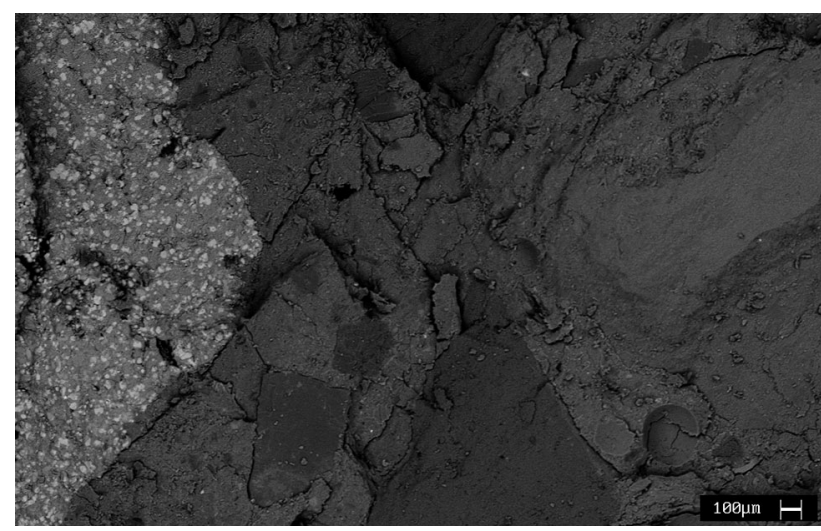

Fig. 7 SEM-BSE image of Mix E-SF

grains, whereas the slag aggregate is dense and compact. Very few pores are observed in some zones of the slag particle boundary (dark grey), and are mainly concentrated where the crack is propagating; the border areas are adherent with the cement paste.

Figure 7 shows instead a slag particle surrounded by the cement matrix of Mix E-SF: the paste appears less compact than Mix E1, particularly in the nearest of the slag aggregates, probably due to the higher absolute water content in the mixture. The cracks develop along the cementitious matrix, and a more distinct band is present between the slag and the paste.

\section{Conclusions}

In this work, some results of an experimental campaign about the potential use of EAF slag in cement-based materials are shown, aiming to give some insights about the important characteristics of the slag and its compatibility in concrete. Particularly, a mechanical characterisation was performed, showing the effects of substituting siliceous aggregates with slag on compressive, tensile strength and elastic modulus. The performances are, in all the cases, significantly enhanced: from this work it is suggested that those improvements are gained both by a higher quality of the slag aggregate (in terms of density and strength), and by an improvement of the bond between EAF slag and the cementitious matrix. This result was also obtained recently by other authors, who obtained a singular morphology of the ITZ when EAF slag is used, which enhances concrete mechanical properties.

The positive results obtained in terms of mechanical strength allowed designing concrete mixtures with the desired strength and workability class, and with a significantly reduced environmental impact. Mix E2, for instance, is characterised by $50 \mathrm{~kg} / \mathrm{m}^{3}$ less cement, reaching about $30 \%$ higher compressive strength than the conventional concrete. This allows improvements in carbon saving and in reducing the environmental emissions of concrete industry.

Acknowledgments The authors would like to acknowledge Mr. Nicola Milan from Zerocento Srl and Mr. Daniele Pozzobon from Cementi Candeo S.p.A., respectively, for supplying the EAF slag and the cement. The authors acknowledge also Ms. Simone Alber, Mr. Tiziano Gheno and Mr. Pietro for their help during the experimental campaign.

\section{References}

1. Mehta PK (2002) Greening of the concrete industry for sustainable development. Concr Int 24(7):23-29

2. Thomas C, Setién J, Polanco JA, Alaejos P, Sánchez De Juan M (2013) Durability of recycled aggregate concrete. Constr Build Mater 40:1054-1065. doi:10.1016/j.conbuildmat.2012.11.106

3. Etxeberria M, Marí AR, Vázquez E (2007) Recycled aggregate concrete as structural material. Mater Struct 40(5):529-541. doi:10.1617/s11527-006-9161-5

4. Pellegrino C, Gaddo V (2009) Mechanical and durability characteristics of concrete containing EAF slag as aggregate. Cem Concr Compos 31(9):663-671. doi:10.1016/j.cemconcomp.2009. 05.006

5. Manso JM, Hernández D, Losáñez MM, González JJ (2011) Design and elaboration of concrete mixtures using steelmaking slags. ACI Mater J 108(6):673-681

6. Anastasiou EK, Papayianni I, Papachristoforou M (2014) Behavior of self compacting concrete containing ladle furnace slag and steel fiber reinforcement. Mater Des 59:454-460. doi:10. 1016/j.matdes.2014.03.030

7. Poon CS, Shui ZH, Lam L (2004) Effect of microstructure of ITZ on compressive strength of concrete prepared with recycled aggregates. Constr Build Mater 18:461-468. doi:10.1016/j.con buildmat.2004.03.005

8. Faleschini F, De Marzi P, Pellegrino C (2014) Recycled concrete containing EAF slag: environmental assessment through LCA. Eur J Environ Civ Eng 18(9):1009-1024. doi:10.1080/19648189. 2014.922505

9. Pasetto M, Baldo N (2011) Mix design and performance analysis of asphalt concretes with electric arc furnace slag. Constr Build 
Mater 125(8):3458-3468. doi:10.1016/j.conbuildmat.2011.03. 037

10. BS 812-110 (1990) Testing aggregates. Methods for determination of aggregate crushing value (ACV). BSI, London

11. Pellegrino C, Faleschini F (2013) Experimental behavior of reinforced concrete beams with electric arc furnace slag as recycled. ACI Mater J 110(2):197-206

12. Fronek B, Bosela P, Delatte N (2012) Steel slag aggregate used in Portland Cement Concrete. U.S. and International perspectives. Transp Res Rec J Transp Res Board 2267:37-42

13. Pellegrino C, Cavagnis P, Faleschini F, Brunelli K (2013) Properties of concretes with black/oxidizing electric arc furnace slag aggregate. Cem Concr Compos 37:232-240. doi:10.1016/j. cemconcomp.2012.09.001

14. Manso JM, Gonzalez JJ, Polanco JA (2004) Electric arc furnace slag in concrete. J Mater Civ Eng 16:639-645. doi:10.1061/ (ASCE)0899-1561(2004)16:6(639)

15. Arribas I, Santamaría A, Ruiz E, Ortega-López V, Manso JM (2015) Electric arc furnace slag and its use in hydraulic concrete. Constr Build Mater 90:68-79. doi:10.1016/j.conbuildmat.2015. 05.003
16. EN 197-1 (2006) Cement-Part 1: Composition, specification and conformity criteria for common cements. Comité Européen de Normalisation, Brussels, Belgium

17. Daugherty KE, Saad B, Weirich C, Eberendu A (1983) The glass content of slag and hydraulic activity. Silic Ind 4:107-110

18. EN 206-1 (2006) Concrete-Part 1: Specification, performance, production and conformity. Comité Européen de Normalisation, Brussels, Belgium

19. EN 12390-4 (2000) Testing hardened concrete-compressive strength—specification for testing machines. Comité Européen de Normalisation, Brussels, Belgium

20. EN 12390-6 (2009) Testing hardened concrete-tensile splitting strength of test specimens. Comité Européen de Normalisation, Brussels, Belgium

21. EN 12390-13 (2013) Testing hardened concrete-determination of secant modulus of elasticity in compression. Comité Européen de Normalisation, Brussels, Belgium

22. Scrivener KL, Crumbie AK, Laugesen P (2004) The interfacial transition zone (ITZ) between cement paste and aggregate in concrete. Interface Sci 12(4):411-421. doi:10.1023/B:INTS. $0000042339.92990 .4 \mathrm{c}$ 